\title{
GASTRIC ULCER, WITH PERFORATION OF THE ANTERIOR AND POSTERIOR WALL OF THE STOMACH.
}

\author{
Br JOSEPH REDMOND, F.K.Q.C.P.; \\ Physician to the Mater Misericordiæ Hospital, and to the \\ Fever Hospital, Cork-street.
}

[Read in the Section of Pathology, May 1, 1889.]

THE specimen which I have the honour to exhibit before the Pathological Section of the Royal Academy of Medicine was removed from a patient of mine who died in the Mater Misericordiæ Hospital on 7th February, 1889.

M.B., aged twenty-six ; servant; unmarried ; was admitted into the Mater Misericordiæ Hospital on the 4th February, 1889. She had recently been under treatment in one of the Dublin hospitals for ulcer of the stomach, but left, as her health had considerably improved. She stated that on Friday, the 1st February, about one week after her departure from hospital, when stooping over a tub washing some clothes she was seized with vomiting and severe pain in the stomach. Her abdomen became rapidly swollen, and, feeling very weak, she was helped to bed by a friend. She remained in bed for three days, but as there was no improvement in her condition she was brought to hospital on the evening of the 4 th February.

On admission her condition was as follows:- She suffered from severe pain in the stomach, accompanied by constant vomiting; temperature was slightly raised; pulse small, rapid, and feeble; respiration thoracic. On examining the abdomen it was found to be greatly swollen, tender on pressure, and tympanitic all over.

5th February.-States she feels much better; vomiting ceased during the night, and pain is not so severe; pulse stronger and not so rapid. 
6th February.-At about 4 o'clock in the evening she complained of severe pain in the stomach, which was relieved by treatment. About midnight she was again seized with an intense pain in the stomach, which was accompanied by a sensation as if some fluid had been poured out into the cavity of the abdomen. Symptoms of collapse now gradually developed, and the patient died at 12 noon on the 7 th February, consciousness being retained till about one hour before death.

The post-mortem examination was made by Dr. M'Weeney, who has given me the following report of it:-

"On post-mortem examination death was found to be due to acute purulent peritonitis following double perforation of the wall of the stomach.

"The anterior wall of the stomach was found to be glued to the under-surface of the anterior thin margin of the liver. On examining the stomach two perforating ulcers were found, one on the anterior wall, the other on the posterior wall, situate exactly opposite one another, somewhat nearer the lesser than the greater curvature and about midway between the cardiac and pyloric ends, the opening in the anterior wall being the older, as evidenced by the presence of lymph, which glued it to the under surface of the liver. The opening in the posterior wall had no such external appearance, and the contents of the stomach had freely passed through the perforation into the lesser cavity of the peritoneum." 